\title{
Interview
}

\section{DAM in marketing operations and the emergence of customer engagement objects - An interview with Chetan Saiya, CEO of Assetlink}

\begin{abstract}
Chetan Saiya
is the founder, chairman and CEO of Assetlink. Assetlink's industry leading solutions for Marketing Operations Management are a result of Chetan's vision and his understanding of marketing operations challenges faced by Global 2000 companies. Before starting Assetlink, Chetan was CEO of MediaWay, a multimedia database management company that he founded, and Tandem Computers, a fault tolerant computing company. He has done his MS in Computer Engineering from University of Notre Dame, Indiana, and Bachelor of Technology in Electrical Engineering from the Indian Institute of Technology (IIT), Bombay.
\end{abstract}

ABSTRACT From primarily being a tool involved in structuring, organizing and managing the digital content, Digital Asset Management (DAM) now bridges the wide gap between a Customer Relationship Management (CRM) solution and outbound or inbound marketing programs. Chetan Saiya, CEO of Assetlink Corporation speaks with Michael Moon on the crucial role DAM plays as an integrated part of an in-trend business process all of the way from planning, to workflows, to actual creation, distribution and actual tracking in the distributed environment.

Journal of Digital Asset Management (2010) 6, 124-129. doi:10.1057/dam.2010.3

Keywords: Digital Asset Manager (DAM); marketing operations management (MOM); marketing resources management (MRM); enterprise marketing management (EMM); Assetlink

MM: We are here with Chetan Saiya, the CEO of Assetlink. Could you give us a brief summary of your current role and professional background?

CS: I am the CEO of Assetlink Corporation. When we founded Assetlink in 1997, we initially focused on Digital Asset Management (DAM), working primarily with Fortune 500 corporations. As we started on this journey, we continually addressed those gaps we uncovered beyond DAM, such as approvals and overall workflow processes. This led us into broader categories of planning, budgeting and calendaring of marketing management. Eventually, we retraced our steps and discovered that we had defined and built a whole new category of software - what we now call
Marketing Operations Management (MOM) that parallels to what Gartner defines as Marketing Resource Management (MRM), what other analyst firms call Enterprise Marketing Management. In essence, that is the Assetlink story.

Prior to Assetlink, I managed what we then called rich media. Starting in 1991, I built underlying database technologies to manage what we used to call large rich objects. From 1992 to 1995 , companies commissioned similar solutions over and over again, all to manage images, videos, and rich or formatted text. We stepped back and said, 'This seems like a new application category' and named it 'multimedia asset management'. In effect we had created and released, what is, most likely, 
one of the first commercially available enterprise DAM systems as far back as 1993-1994!

MM: Wonderful background. I would like to explore with you how DAM continues to play a growing role in marketing operations. Perhaps, you can quickly survey some of the key challenges that marketers face today?

CS: Marketers today are experiencing great turbulence. We believe that marketing, as a discipline, will have to dramatically transform itself into a more capable digital operation that can ride the great waves of change. We see three or four distinct areas of challenge that will affect marketing. We also believe that most or all of these areas of challenge boil down to the underlying challenges of creation of digital assets, management of content, and secure distribution of content and digital assets.

Let's address the first area of challenge: the proliferation of media types and media channels that marketers use today to attract and engage customers.

Take the typical vice president of marketing in a consumer packaged goods company.

Ten years ago he or she only had to deal with traditional advertising on television, radio, national magazines, local newspapers, and some amount of promotions and packaging design. Today, marketing heads must also deal with search engine optimization, customer engagement sites, sponsoring activities, blogs, mobile coupons and other social media such as Facebook, My Space, Twitter, etc.

As a result of media and channel proliferation, marketers must grapple with a dramatic increase in the amount of content to manage, distribute and repurpose. However, they must accomplish that using the same number of staffer. So, doing more with the same number of people becomes critical.

Let's take another area of challenge: globalization and the need to release the more or less the product in multiple languages, media formats and geographies. Again, globalization represents a good reason for content repurposing, effective management of the underlying reusable digital assets, and unified brand voice and messaging across this whole diverging complex environment.

Shrinking product life cycles has become another area of challenge, especially as the release of a globally marketed product must sync up with promotions across various media channels. Shorter product life cycles eliminate the possibility of managing all your content in a physical form. Rather, you must make available all the usable or reusable digital assets to your entire global marketing teams and partners.

Finally, regulatory compliance has become area of challenge for many marketers. Marketers can no longer tolerate unconnected information and orphaned content. This is especially true industries such as pharmaceuticals, where claims management becomes a key issue - where every message that marketer puts on a brochure, package, ad, web page or user guides has to be pre-approved with every change tracked and dated. This means that marketers need an integrated DAM that manages text, rich media and content.

You know, as we drive deeper and deeper in the management of marketing, we see DAM at the center of almost every solution. MM: Chetan would describe some of the basic systems that support marketing operations today and indicate how DAM supports or provides a bridge to many of these systems. CS: We see three key pillars to marketing operations. DAM represents the first pillar. When you ask marketers what they are doing at a particular moment of their workday, they typically describe content creation activity. This includes creating, reviewing, and approving new advertisements, direct mail pieces, print collateral and package design. Because a good DAM with strong workflow manager helps you manage the creation, development, and distribution of marketing content and materials, DAM has become one of the three pillars of marketing operations.

Next, marketers do not work in isolation. They work in a collaborative environment with business users, product managers, regulatory research and legal, as well as external partners such as creative or direct mail agencies, printers, pre-press and so on. So marketers need a variety of processes and tools to create, manage and deliver all sorts of media products in an efficient manner - effective process management that adds efficiency and effectiveness to their programs and their project status. Thus, collaboration and workflow represent the second pillar of marketing operations. 
The third and important pillar of marketing operations entails customer engagement: how firms attract, serve and keep profitable customers, hopefully for life or at least a very long time. At the end of the day, all digital assets and all the processes entail engaging a prospective customer with the company's goods and services in a more efficient and profitable manner.

Of the three pillars of MOM, we have found that DAM becomes the core of both process management and customer engagement. That's because a stronger and more mature capability of DAM leads the way to more efficient and simpler processes and a better, more consistent view of customer engagement as a process and life cycle.

MM: In a practical sense, how does a marketing organization develop a more robust, mature DAM services capability?

CS: Okay. Many marketers and technology providers describe DAM as using repository to collect and manage all their marketing content - as a library or service. However, DAM as a capability has continued to evolve, adding things like workflow management, project management, automated publishing, smart collateral and marketing information management.

Overall the evolution of DAM introduces a few new concepts. One, we now must consider the life cycle of digital assets versus the life cycle of just content. In practice, this means developing a framework for evolving metadata, workflows and business rules. Second, the technology by which to deliver DAM directly correlates with the variable bandwidth and the infrastructure around connectivity. This means that Moore's Law applies to DAM: every 2 or so years, bandwidth and storage doubles with zero additional cost. Thus, DAM usage and its efficiencies should continue doubling every 2 or so years. MM: From what you have just mentioned, it strikes me that we have two dimensions of innovation. That is, in 5 years almost everything is going to be 10 times faster or 10 times cheaper or some combination of faster and cheaper; that 10 years from now DAM and related digital capabilities will become 100 times faster, 100 times cheaper or a combination.
That means that the digital will drive two dimensions of digital universe: the world of consumers using faster, cheaper technology to improve how they live, work, play and learn, including how they find and interact with brands, service providers and social networks; the world of enterprises using faster, cheaper technology to attract and engage customers.

So, consumers will use 10-100 times faster, cheaper technology, especially their mobile Web devices and Web-connected home entertainment systems, to buy, shop or procure the things that they want to consume. This in turn puts tremendous pressure on marketing organization to meet customers' growing demand for 10-100 times faster consumption of digital content and services. That means that vendors seeking engagement with consumers must satisfy this exploding demand for content and services, calling attention to the marketing or engagement infrastructure of vendors.

Thus, marketers must continually innovate internal processes by which they attract, serve and keep profitable customers for life. Marketer must evolve their capabilities of traditional marketing to increase the immediate and every changing demands of customer engagement. So, the companies will continue finding themselves in this digital environment that not only expands 10 times bigger and 10 times faster every 5 years. Companies need ways to really exploit the opportunities inherent in that rapidly expanding digital space.

CS: Right. This is again where the newer, more evolved role of DAM plays a strategic role. I think what you are saying is that there is going to be a very large Internet pipe that connects marketer and his or her customers. And it is not only large, but it is always going to be connected; there is going to be a higher volume of delivery on both sides as well as more connectedness.

We see a few very interesting implications about digital assets. In the past, we thought of digital assets as something to keep in a locked box or a 'vault' - like cash, jewelry, fine art, etc.

In this view, a digital asset represents access with low connectivity and very, very low bandwidth. As bandwidth and connectivity improved, as it has today, we have less incentive to create physical masters of assets; rather, we 
have greater incentives to create and maintain digital masters and transform these assets into physical expression when and where we need high resolution versions.

As so many functions have migrated to the cloud (off-premise, on-demand infrastructure), more of the digital assets will live in the cloud in easily transformed assets - so long as you can track and manage them.

So now let us fast forward to the future where we have very large pipes - very fast Internet connections and very fast computing devices - and we can access anything from anywhere and everything that everyone cares about remains online and always connected.

This means that your digital assets never have to leave your asset repository, or that whole cloud becomes a DAM system. Everything that exists today in your DAM system is now distributed across your centralized server as well as to the user's environment, either to a computer, a tablet or a small mobile device.

MM: So, Chetan, let me expand upon an idea that you just identified. I remember earlier in my career, I proofed ads using four-color transparencies, sign-off forms and expensive same-day couriers. Then desktop publishing came along and we started sending off EPS files directly to the prepress house or printer, getting back hardcopy digital proofs. And then along came remote proofing, where the high-resolution file would stay at the printer or the packaging manufacturer, and I would access it through specialize software applications and expensive high-speed Internet connections. Finally, it's just a browser on a Mac with an ICC color profile and cheap WiFi connectivity. CS: Yes. That's a perfect example of we called a pillar of marketing operations. With faster bandwidth and DAM system, you made your process much simpler and took about a lot intermediate steps, hand-offs, delays and costs.

MM: So far you have addressed the fact that orphan pieces of content or unconnected information that should become connected to the collection of assets and the creative brief what's the communication objectives, media formats, where it was used, feedback and so on. That is an information management problem of a larger context.
I also wanted to address the high turnover rate or downsizing in marketing organizations today and many people feel so deeply ingrained in how they get things done and where information and projects artifacts exist. As marketing organization downsize or reorganize they often encounter a staggering institutional memory loss. What can marketing executives do to offset this loss of knowledge - skilled knowledge workers that now walk out the door and never returns?

CS: This is something we all are familiar with. At the end of the day, what we are talking about is how to capture and retain the knowledge - not just how an asset was created, but also why was it created. Our clients have begun to derive very rich sets of metadata from their workflows, automatically derived from integrating and configuring DAM and MRM tools to how they work.

I'm speaking to this broader area of marketing knowledge management, where we are not just thinking of this as a repository of files, but as a higher destination of knowledge.

Let's start by asking a few questions. Of all the things that we do as marketers, what is effective? What is not effective and why? What must we start doing better? Who does this particular thing really well? What do they do that others do not? How do we capture the really effective or efficient ways of getting things done and propagate those others in the firm or supply chain?

Answers to those questions inform what we can call 'best practice management'. The practice of capturing best practices in a marketing operation has become very, very important. Why? Because we no longer must deal with just two or three different kinds of content; rather, we must deal with dozens and dozens of types and forms.

Gone are the days of simple advertising and simple product packaging with some promotional pieces; we have hundreds of new media types and hundreds of different ways of interacting with the customers. Each and every one of these customer interactions required different types of content and digit assets.

So how do we create an institutional memory to manage all of this different information? This whole area around best practice creation and best practice building and 
a marketing knowledge has become very important for these companies. And it starts a very, very strong DAM system coupled with process manage, workflow builders and dashboards - all things that we think Assetlink leads in the industry.

MM: Chetan, would you consider it accurate that DAM represents the direct management of big media objects, metadata describing the object and user experience of using those media objects in proper way?

CS: Yes. And I think the whole concept of metadata has evolved in rather dramatic ways. At first we talked about metadata and its purpose: how you can find and retrieve that assets in an easy way. So metadata represented keywords and descriptions of the asset; how we retrieve it from among thousands or hundreds, thousands or millions of assets.

Today, as we integrate digital assets into these broader processes, starting with planning and budgeting, then to the creation, review, approval, and distribution of assets, and finally to download, reuse and archival of the asset or business content (proposals, presentations, etc) - an entire life cycle with each phase and element expressed in metadata. Thus, the initial strategy and conceptualization sessions that preceded the creation of marketing campaigns and its content, become crucial sources of the metadata or as we call it now, the asset profile.

MM: And yet, while we manage it as metadata, oftentimes when we want to publish a web page or build an ad, the metadata becomes published content. This includes product descriptions, marketing claims, guidelines, etc. And it's about getting one version of the marketing truth, from a DAM perspective, as process or life cycle metadata.

CS: Agreed. We need a broader and better term for this, because most metadata represents some very limited piece of information. So let's step back and ask why are we doing all this? Ultimately, I believe it's all about engaging customers; why we create content. So, then, we do we orphan or deleting all this strategy and planning information the first place? It's all very useful in understanding how marketing engages with the customer.

MM: Well, two priorities come to mind: first, we create content to engage customers; second, we create content that enables or supports a feedback loop in terms of how well we engaged the customer.

CS: So, it is an engagement interaction data of our customers' behavior. So, we now have an evolution of a customer engagement to our broader, newer, bigger form, all deeply informed by DAM!

MM: Let's us call that the fourth era of digital assets, where we define a digital asset not just as a searchable file that we can transform and understand and how it gets consumed and tracked. Rather, this fourth era of digital assets enables us to talk about customer engagement objects - a collection media, metadata, marketing claims and tracking consumption data as well as tracking consumption through the life cycle, not just of the digital asset, but of the pattern of engagement - so it is part of a much larger formulation of how we as a company attract, serve and keep profitable customers for life. CS: Absolutely.

MM: And DAM really then becomes the bridge between things like CRM and other outbound or inbound marketing programs with the operational planning, budgeting, analytics, what is going on, and now it is producing this high-grade thing, this customer engagement object, which is either used in outbound or inbound communications, but it is kind of ultimately what every company produces. If you have a customer relationship, you by definition create customer engagement objects. CS: You are going to ask your customer relationship to be a business, which means everyone has a need for this customer engagement object.

MM: Well, to the extent that you have as a primary directive to find and serve customers, yes.

CS: Which I hope every one of us does. MM: Well, you know you could say that some public institutions like the Internal Revenue Service basically do not have customers.

CS: Okay, but they will keep all our text filing as DAM objects.

MM: Right. As we near the end of our interview today, do you have any other practical next-steps that marketers might consider taking?

CS: As we just laid it out, we should not think of a DAM system as a bucket where we put 
things. Rather, let's think about digital assets as an integral part of a business process. All the way from planning, to workflows, to the actual creation, and then to the part around distribution and actual tracking in the distributed environment so that you get constant feedback and potentially affect a positive result on your engagement with the customers. That is one aspect.

Second, we should think about digital assets in every context whether one talks about planning, budgeting, or any or every media type. Let's not isolate things in a DAM repository; rather let's curate collections of official and alternate-but-unused versions of product or packaging design, along with photos and web pages as an integrated set or collection.

Third, we must think about how to build a core competency in managing your own digital assets and not an outsourced work of vendors. Why? Ultimately, we must manage digital assets as integral components of how we engage customers. And you do not want to outsource that!

MM: Wonderful! Well that sounds like a great point to conclude with. Chetan, thank you for the time today and I look forward to continuing our conversation on the topic of DAM, and the emergence of customer engagement objects as the ultimate digital asset for every company.

CS: I look forward to that, too. 